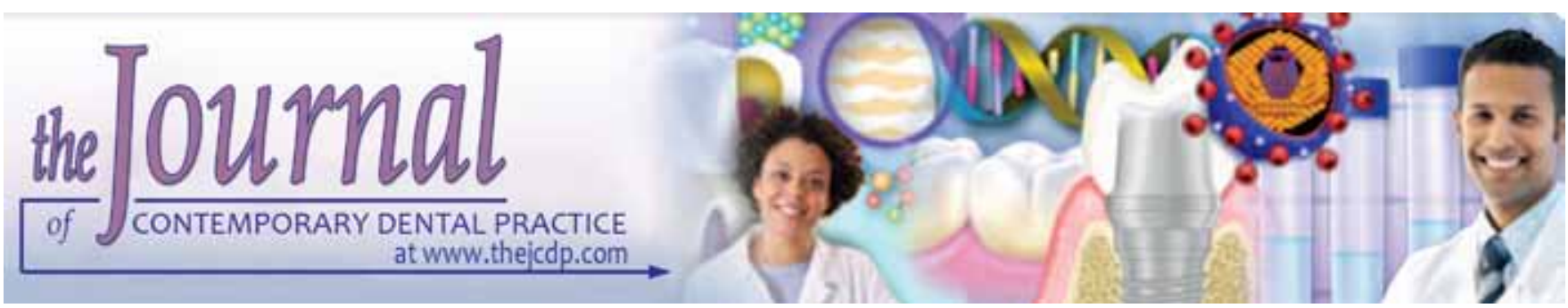

\title{
Utilization of Dental Services in Public Health Center: Dental Attendance, Awareness and Felt Needs
}

\author{
${ }^{1}$ Preksha Pewa, ${ }^{2}$ Bharath K Garla, ${ }^{3}$ Rushabh Dagli, ${ }^{4}$ Geetika Arora Bhateja, ${ }^{5}$ Jitendra Solanki
}

\begin{abstract}
Background: In rural India, dental diseases occur due to many factors, which includes inadequate or improper use of fluoride and a lack of knowledge regarding oral health and oral hygiene, which prevent proper screening and dental care of oral diseases. The objective of the study was to evaluate the dental attendance, awareness and utilization of dental services in public health center.
\end{abstract}

Materials and methods: A cross-sectional study was conducted among 251 study subjects who were visiting dental outpatient department (OPD) of public health centre (PHC), Guda Bishnoi, and Jodhpur using a pretested proforma from month of July 2014 to October 2014. A pretested questionnaire was used to collect the data regarding socioeconomic status and demographic factors affecting the utilization of dental services. Pearson's Chi-square test and step-wise logistic regression were applied for the analysis.

Results: Statistically significant results were found in relation to age, educational status, socioeconomic status and gender with dental attendance, dental awareness and felt needs. p-value $<0.05$ was kept as statistically significant.

Conclusion: The services provided in public health center should be based on the felt need of the population to increase attendance as well as utilization of dental services, thereby increasing the oral health status of the population.

Keywords: Dental services, Healthcare, Public health center, Utilization.

How to cite this article: Pewa P, Garla BK, Dagli R, Bhateja GA, Solanki J. Utilization of Dental Services in Public Health Center: Dental Attendance, Awareness and Felt Needs. J Contemp Dent Pract 2015;16(10):829-833.

\footnotetext{
${ }^{1-5}$ Department of Public Health Dentistry, Vyas Dental College and Hospital, Jodhpur, Rajasthan, India
}

Corresponding Author: Preksha Pewa, Postgraduate Student, Department of Public Health Dentistry, C-7 Shiv Om Shakti, Pewa Nagar, Near Subham Farm House, Pal Road Jodhpur, Rajasthan, India, Phone: 09950837778, e-mail: ppewa1988@gmail.com

\section{Source of support: Nil}

Conflict of interest: None

\section{INTRODUCTION}

A health center or community health center is a clinic staff by a group of general practitioners and nurses. The common services provided in health centres includes family practice and dental care, but in some of them internal medicine, pediatric, women's care, family planning, pharmacy, lab, and more services will also be provided. In 2006, the National Association of Community Health Centers (NACHC) implemented a model according to which free and rapid HIV testing of all the patients between the age groups of 13 to 64 years during routine medical and dental visits. ${ }^{1}$

Oral diseases created burden on public health in India, among them 60 to $65 \%$ of the population is affected by dental caries and 50 to $90 \%$. According to research, higher rates of dental diseases occur in rural areas. The widespread of poor oral health results in deterioration of health of the population as well as utilization of services in health systems level, dental caries and periodontal disease deteriorate health and well-being of individual results in decrease economic productivity, and here by act as significant risk factors for other health ailments. ${ }^{2}$

In rural India, dental diseases occur due to sociocultural factors, which includes inadequate or improper use of fluoride and a lack of knowledge regarding oral health and oral hygiene, which prevent proper screening and dental care of oral diseases. ${ }^{2}$

Keeping all the above points in view, a study was carried out aiming to see the 'Utilization of dental services provided in public health center-dental attendance and awareness' we conducted our study in public health center located at rural area near Jodhpur city at Guda Bishnoi village, as no other previous study has been done yet. 
This study had an objective evaluate the dental attendance, awareness and utilization of dental services in public health center.

\section{MATERIALS AND METHODS}

A cross-sectional study was conducted among all the study subjects who were visiting dental OPD of PHC, Gudavishnoi, and Jodhpur. This study was carried out for the period of 4 months that is month of July 2014 to October 2014. The data were collected by using pretested questionnaire.

Patient who were not willing to respond to the questionnaire were excluded.

Ethical clearance was obtained from the ethical committee of Vyas Dental College and Hospital, Jodhpur and informed consent was taken from PHC as well as from study subjects. Prior to the start of study, subjects were informed regarding the research work.

A pretested questionnaire was used to collect the data regard socioeconomic status and demographic factors affecting the utilization of dental services.

The questionnaire were filled in the presence of the dentist posted in PHC. The questionnaire reliability was checked by taking 30 individuals in consideration prior to data collection after that in total 251 study subject's data was collected.

The collected data were retrieved by using excel sheet and was transferred into suitable statistical software SPSS Version-20, Pearson's Chi-square test and stepwise logistic regression were calculated for the analysis. p-value $<0.05$ was kept as statistically significant.

\section{RESULTS}

Table 1 shows the frequency distribution of study subjects according to sociodemographic characteristics. Out of 251 patient, maximum number of patient (61) falls in the age group of 20 to 30 years (24.3\%) 50 years and above 54 (21.5\%), 30 to 40 years were $52(20.7 \%), 40$ to 50 years 44 $(17.5 \%), 10$ to 20 years $33(13.1 \%)$ and $>10$ years $07(2.8 \%)$. A total of $30.7 \%$ were illiterate and only $18.7 \%$ were graduate and above. A total of $34.7 \%$ of study subjects were employed and only $12.4 \%$ were belonged to government services and $41.4 \%$ belongs to lower middle classes.

Table 2 shows the frequency distribution of study subjects according to their dental attendance and awareness. The total of $43.8 \%$ of study subjects visited the health center for the first time and $29.9 \%$ were coming for the recall check-up from last 2 years. Among the total study subjects, $83.7 \%$ were aware about the free preventive dental program is delivering in public health center. The various services provided to study subjects according to diagnosis which include restoration (39.4\%),
Table 1: Distribution of study subjects according to sociodemographic characteristics

\begin{tabular}{|c|c|c|}
\hline Variable & $\begin{array}{l}\text { Attendance of } \\
\text { patient in the public } \\
\text { health center }(n)\end{array}$ & Percentage \\
\hline \multicolumn{3}{|l|}{ Age (years) } \\
\hline$>10$ & 07 & 2.8 \\
\hline 10-20 & 33 & 13.1 \\
\hline 20-30 & 61 & 24.3 \\
\hline $30-40$ & 52 & 20.7 \\
\hline $40-50$ & 44 & 17.5 \\
\hline 50 years and above & 54 & 21.5 \\
\hline \multicolumn{3}{|l|}{ Education } \\
\hline Illiterate & 77 & 30.7 \\
\hline Primary school & 61 & 24.3 \\
\hline High school & 65 & 25.9 \\
\hline Graduate & 47 & 18.7 \\
\hline Professional & 01 & 0.4 \\
\hline \multicolumn{3}{|l|}{ Occupation } \\
\hline Business & 83 & 33.1 \\
\hline Government services & 31 & 12.4 \\
\hline Others & 50 & 19.9 \\
\hline Unemployed & 87 & 34.7 \\
\hline \multicolumn{3}{|l|}{ Socioeconomic status } \\
\hline Upper & 25 & 10 \\
\hline Upper-middle & 51 & 20.3 \\
\hline Lower-middle & 104 & 41.4 \\
\hline Upper-lower & 47 & 18.7 \\
\hline Lower & 24 & 9.6 \\
\hline
\end{tabular}

$\mathrm{n}$ : Number of patients in a particular category

Table 2: Distribution of study subjects according to their dental attendance and awareness

\begin{tabular}{|c|c|c|}
\hline Variable & $\begin{array}{l}\text { Attendance of patient in the } \\
\text { public health center }(n)\end{array}$ & Percentage \\
\hline \multicolumn{3}{|c|}{ Are you visiting the health center for the first time? } \\
\hline Yes & 110 & 43.8 \\
\hline No & 141 & 57.2 \\
\hline
\end{tabular}

If no, when was the last treatment done?

1 year $\quad 66 \quad 26.3$

$1-2$ years $\quad 75 \quad 29.9$

2-5 years $\quad 1 \quad 0.4$

More than $5 \quad 0 \quad 0$

years

Are you aware about the free preventive dental programe is delivering in public health center?

$\begin{array}{lll}\text { Yes } & 210 & 83.7\end{array}$

No $41 \quad 16.3$

What type of services is provided in the public health service free of cost?

\begin{tabular}{lcc} 
Extraction & 56 & 22.3 \\
Cleaning & 31 & 12.4 \\
Restoration & 99 & 39.4 \\
All of the above & 65 & 25.9 \\
Does the health center maintain the health records? \\
Yes & 251 & 100 \\
No & 00 & 0 \\
\hline
\end{tabular}

$\mathrm{n}$ : Number of patients in a particular category 
extraction (22.3\%) and cleaning (12.4\%). Table 3 shows the distribution of study subjects according to their felt needs. The most common dental problem was pain $(61.8 \%)$ followed by difficulty of chewing $(17.9 \%)$ and bad smell in mouth (7.6\%). Only $6.4 \%$ were come for the routine check-up.

Table 4 shows step-wise regression analysis in Utilization of services. Significant regression was found in age, gender and education $(\mathrm{R}-0.273,0.130,0.172$, $p=-0.000,0.039,0.006$, respectively).

There is significant association between dental attendance and awareness with different age groups. Twenty to 30 years old individual have more dental attendance and awareness in relation to the first visit to health center, last treatment done and services provided to public health center $\left(\mathrm{x}^{2}-18.016,30.378,71.103, \mathrm{p}=\right.$ $-0.003,0.011,0.000$ respectively). There is significant association between felt needs and different age groups. Fifty years and above older individual have pain in relation to the reason of attending the clinic $\left(x^{2}-37.477\right.$, $\mathrm{p}=0.011$ respectively).

There is significant association between dental attendance and awareness with educational status. The most common were the high school individual who received restorations as the treatment in the public health service $\left(x^{2}-60.298, p=0.000\right.$, respectively).

There is significant association between dental attendance and awareness with socioeconomic status. Lower-middle group individuals have more awareness in relation to free preventive dental program delivered in PHC and the type of service provided in PHC $\left(x^{2}-14.375\right.$,

Table 3: Distribution of study subjects according to their felt needs

\begin{tabular}{|c|c|c|}
\hline Variable & $\begin{array}{l}\text { Attendance of patient in } \\
\text { the public health center ( } n \text { ) }\end{array}$ & Percentage \\
\hline \multicolumn{3}{|c|}{ Are you coming to the clinic because of } \\
\hline Pain & 155 & 61.8 \\
\hline Bleeding gums & 16 & 6.4 \\
\hline $\begin{array}{l}\text { Difficulty of } \\
\text { chewing }\end{array}$ & 45 & 17.9 \\
\hline $\begin{array}{l}\text { Bad smell in } \\
\text { mouth }\end{array}$ & 19 & 7.6 \\
\hline Routine check-up & 16 & 6.4 \\
\hline
\end{tabular}

$\mathrm{n}$ : Number of patients in a particular category $x^{2}-26.710, p=0.006, p=0.009$ respectively). Significant association between felt needs and socioeconomic status. Lower-middle group individuals have pain in relation to reason for attending the clinic $\left(x^{2}-27.929, p=0.032\right.$, respectively).

There is significant association between dental attendance and awareness with gender. Male individuals have more dental attendance and awareness in relation to the first visits to health center and type of services provided in PHC's $\left(x^{2}-7.758,11.401, \mathrm{p}=-0.052,0.010\right.$, respectively).

\section{DISCUSSION}

Health is a fundamental right of every human being without discrimination related to race, religion and socioeconomic status. Several challenges were faced by rural population in delivery of oral healthcare services due to deficiency of manpower, poor accessibility, affordability, and availability. The factor affecting utilization of health care services includes affordability and accessibility and need of the population toward services. ${ }^{3}$ In a developing country accessibility of oral health services among rural population is often difficult. So, the present study was designed to evaluate the dental attendance, awareness and utilization of dental services in public health center. The study subject includes 251 samples located at rural area near Jodhpur city at Guda Bishnoi village.

It was revealed from the present study that most of the patients who were attending public health center falls in the age group of 20 to 30 years $(24.3 \%)$. Service were less utilized by the children and adult $<20$ years which were not in agreement with other studies. ${ }^{3-5}$ It may reflect older individual attitude toward their oral health and parents concerned toward their child's oral health.

In the present study, utilization of dental services was higher among females as compared to males which is similar to other studies finding. ${ }^{3,5-8}$ It may be due to the fact that Females utilize more dental services to look good and being housewives they have enough time to attend the outreach programs, on the other hand men were bread earners hence, utilize less dental services.

A total of $55.0 \%$ patients attending PHC were illiterate or had primary education. The study showed similarity to a study carried out by Shelja et al. ${ }^{3}$

Table 4: Stepwise regression analysis showing utilization of services

\begin{tabular}{|c|c|c|c|c|c|}
\hline Variables & Mean & Std. dev. & $R$-value & $p$-value & Significance \\
\hline Age & 38.171 & 17.777 & 0.273 & 0.000 & S \\
\hline Gender & 1.39 & 0.488 & 0.130 & 0.039 & S \\
\hline Education & 2.338 & 1.113 & 0.172 & 0.006 & $S$ \\
\hline Occupation & 2.561 & 1.267 & 0.857 & 0.408 & NS \\
\hline Socioeconomic status & 2.968 & 1.078 & 0.859 & 0.499 & NS \\
\hline
\end{tabular}

S: Significant; NS: Non-significant 
Around $41.4 \%$ of the study population belongs to lower middle class. Socioeconomic status of a person plays an important role in his/her willingness toward dental care. ${ }^{9-11}$ The information regarding socioeconomic factors belonged to lower class $(9.6 \%)$ and people belongs to government services $(12.4 \%)$ explaining the nonutilization of the services.

This finding supports the assumption that in developing countries most of the people visit for dental care services when they were in pain (5.2\%). The study clearly suggests for higher demand of emergency care among patients who were visiting in the late stages of dental diseases. This observation is found to be in accordance with that of previous studies conducted more than 10 years ago in the United Republic of Tanzania ${ }^{12}$ and Sijan et $\mathrm{al}^{13}$ and recently in China, ${ }^{14}$ Nigeria ${ }^{15}$ and Sri Lanka ${ }^{16}$ and also a study done by Varenne et $\mathrm{al}^{17}$ and Sri Lanka. ${ }^{18}$ For example, in the United Republic of Tanzania, $86 \%$ of patients who have come for treatment were having pain and the main cause for pain was found to be dental caries. ${ }^{12}$

Studies have revealed that the levels of education as well as financial status are some of the important factors in utilization of dental care. ${ }^{19,20}$ Socioeconomic status of a person plays an important role in his/her willingness toward dental care. ${ }^{21,22}$ The information regarding sociodemographic factors revealed that the most of the subjects were illiterate $(30.7 \%)$, belonged to lower middle group $(41.4 \%)$ and unemployed (34.7\%) explaining the nonutilization of the services.

In present study stepwise regression analysis in utilization of services were taken and the significant regression was found in age, gender and education.

Hence in order to improve the dental attendance, the barriers should be identified and appropriately controlled by providing them education and motivation.

The limitation of the present study was less coverage area, therefore, further investigation should be conducted for affective results.

\section{CONCLUSION}

The dental services utilization in the public health center has been found to be influenced by sociodemographic characteristics of the population. The services provided in public health center should be based on the felt need of the population to increase attendance as well as utilization of dental services, thereby increasing the oral health status of the population.

In short, district health authorities should provide the provision of primary healthcare services among patient's visiting for the first time, that are mainly targeted toward pain relief. Secondly, well-trained and supervised primary health care personnel should be available to provide early and essential care to the rural community so that there is no need to go to the higher center for the treatment.

\section{REFERENCES}

1. Community Health Centers Integrate Rapid HIV Screening Into Routine Primary Care, Leading to Significant Increases in Testing Rates. Agency for Healthcare Research and Quality. Accessed 15 July 2014.

2. Oral Health: Addressing Dental Diseases in Rural India. 2012. Available at: www.ictph.org.in/tps-2011/paper4introduction.html. Accessed 25 Sep 2014.

3. Vashisth S, Gupta N, Bansal M, Rao NC. Utilization of services rendered in dental outreach programs in rural areas of Haryana. Contemp Clin Dent 2012 Sep;3(Suppl 2):164-166.

4. Syrjala AM, Knuuttila ML, Syrjala LK. Reasons preventing regular dental care. Community Dent Oral Epidemiol 1992; 20:10-14.

5. Manski RJ, Magder LS. Demographic and socioeconomic predictors of dental care utilization. J Am Dent Assoc 1998; 129:195-200.

6. Meng X, Heft MW, Bradley MM, Lang PJ. Effect of fear on dental utilization behaviors and oral health outcome. Community Dent Oral Epidemiol 2007;35:292-301.

7. Slack-Smith LM, Mills CR, Bulsara MK, O'Grady MJ. Demographic health and lifestyle factors associated with dental service attendance by young adults. Aust Dent J 2007; 52:205-209.

8. Pizarro V, Ferrer M, Domingo-Salvany A, Benach J, Borrell C, Pont A, et al. The utilization of dental care services according to health insurance coverage in Catalonia (Spain). Community Dent Oral Epidemiol 2009;37:78-84.

9. Jain VKA, Sequeira. PB, Jain JC, Chancy UA, Maliyil MJA, Bhagwandas SCA. Barriers in utilization of oral health care services among patients attending primary and community Health Centres in Virajpet, South Karnataka'. National J Med Dent Res 2013 Apr-Jun;1(3):39-47.

10. Strayer MS, Branch LG, Jones JA, Adelson R. Predictors of the use of dental services by older veterans. Spec Care Dent 1988;8:209-213.

11. Holtzman J, Berg R, Mann J. The relationship of age and gender to fear and anxiety in response to dental care. Spec Care Dent 1997;17:82-86.

12. van Palenstein $W H$, Nathoo ZA. Dental treatment demands among patients in Tanzania. Community Dentist Oral Epidemiol 1990;18:85-87.

13. Poudyal S, Rao A, Shenoy R, Priya H. Utilization of dental services in a field practice area in Mangalore, Karnataka. Ind J Community Med 2010 Jul;35(3):424-425.

14. Du M, Petersen PE, Fan M, Bian Z, Tai B. Oral health services in PR China as evaluated by dentists and patients. Inter Dent J 2000;50:250-256.

15. Oginni AO. Dental care needs and demands in patients attending the dental hospital of the Obafemi Awolowo University Teaching Hospital's Complex Ile-Ife, Nigeria. Nigerian J Med 2004;13:339-344.

16. Ekanayake L, Weerasekare C, Ekanayake N. Needs and demands for dental care in patients attending the University Dental Hospital in Sri Lanka. Int Dent J 2001;51:67-72. 
17. Faso B, Varenne B, Msellati P, Zoungrana C, Fournet F, Salem G. Reasons for attending dental-care services in Ouagadougou. Bulletin WHO 2005 Sept;83(9):650-655.

18. Warnakulasuriya S. Demand for dental care in Sri Lanka. Community Dent Oral Epidemiol 1985;13:68-69.

19. Shah N, Sundaram KR. Impact of sociodemographic variables, oral hygiene practices, oral habits and diet on dental caries experience of Indian elderly a community- based study. Gerodontol 2004;21:43-50.
20. Vargas CM, Yellowitz JA, Hayes KL. Oral health status of older rural adults in the United States. J Am Dent Assoc 2003; 134:479-486.

21. Strayer MS, Branch LG, Jones JA, Adelson R. Predictors of the use of dental services by older veterans. Spec Care Dent 1988;8: 209-213.

22. Holtzman J, Berg R, Mann J. The relationship of age and gender to fear and anxiety in response to dental care. Spec Care Dent 1997;17:82-86. 